to 21 min. Finally, $\mathrm{I}_{\mathrm{Na}}$ were recorded again in normal $\mathrm{I}_{\mathrm{Na}}$ solution (simulate reperfusion).

Results (1) Ischemia effects: In ischemia group, compared with normal $(0.95 \pm 0.04)$, normalised currents (at $-40 \mathrm{mV}$ ) of simulated ischemia were increased to peak at $3 \mathrm{~min}(1.15 \pm 0.08$, $\mathrm{p}<0.01)$, returned at $9 \mathrm{~min}$ and $11 \mathrm{~min}(0.98 \pm 0.12$ and $0.92 \pm 0.12$, $\mathrm{p}>0.05$, respectively), and decreased at $21 \mathrm{~min}(0.56 \pm 0.13$, $\mathrm{p}<0.01)$. At simulated ischemia for $21 \mathrm{~min}$, there were no significant differences among ischemia group, reperfusion group and statin-reperfusion group. (2) Effects of atorvastatin on ischemia myocytes: in statin-ischemia group, there were no differences between nomal and simulated ischemia for 3 min $(0.97 \pm 0.04$ vs $0.92 \pm 0.12, \mathrm{p}>0.05)$. (3) Reperfusion effects: compared with ischemia for $21 \mathrm{~min}$, normalised currents (at $-40 \mathrm{mV}$ ) in reperfusion group were decreased at reperfusion for $3 \mathrm{~min}$ from $0.83 \pm 0.11$ to $0.57 \pm 0.09(\mathrm{p}<0.05)$, and decreased to $0.50 \pm 0.09$ at reperfusion for $9 \mathrm{~min}$ (compared with $3 \mathrm{~min}$ $\mathrm{p}<0.05$ ), while in ischemia group normalised currents were not changed again. And compared with ischemia group, normalised currents (at $-40 \mathrm{mV}$ ) in reperfusion group were decreased at reperfusion for 3 to $9 \mathrm{~min}(\mathrm{p}<0.01)$. (4) Effects of atorvastatin on reperfusion myocytes: compared with ischemia for $21 \mathrm{~min}$, normalised currents (at $-40 \mathrm{mV}$ ) in statin-reperfusion group were decreased at reperfusion for $3 \mathrm{~min}$ from $0.92 \pm 0.04$ to $0.72 \pm 0.05(p<0.01)$. And at reperfusion for 3 to $9 \mathrm{~min}$, normalised currents in statin-reperfusion group were decreased compared with ischemia group, but increased compared with reperfusion group ( $\mathrm{p}<0.01$, respectively).

Conclusions (1) The effects of simulated ischemia on $I_{\mathrm{Na}}$ are time dependent, while $\mathrm{I}_{\mathrm{Na}}$ is transient increased at $3 \mathrm{~min}$, but decreased $21 \mathrm{~min}$ (2) Simulated reperfusion make $I_{\mathrm{Na}}$ more decreased from ischemia condition. (3) Atorvastatin can depress increased $\mathrm{I}_{\mathrm{Na}}$ at the period of early ischemia, and depress decreased $\mathrm{I}_{\mathrm{Na}}$ at the time of reperfusion.

\section{[gw22-e0186] EFFECTS OF SIMULATED ISCHEMIA-REPERFUSION AND ATORVASTATIN ON INA IN RAT LEFT VENTRICULAR MYOCYTES.}

Li Hongshi, Wang Fang, Bian Bo, Wan Zheng, Teng TianmingTianjin Medical University General Hospital, Tianjin, China

10.1136/heartjnl-2011-300867.37

Objective To observe time dependent effects of simulated ischemia-reperfusion on transient sodium currents $\left(\mathrm{I}_{\mathrm{Na}}\right)$ in rat left ventricular myocytes, and effects of atorvastatin on $\mathrm{I}_{\mathrm{Na}}$ in the condition of ischemia and reperfusion.

Methods Fifty-four Wistar rats were used for isolating left ventricular myocytes, which were randomly divided into four groups: ischemia group (normal $\rightarrow$ ischemia $\rightarrow$ ischemia), reperfusion group (normal $\rightarrow$ ischemia $\rightarrow$ reperfusion), statinischemia group (normal $\rightarrow$ ischemia with $5 \mu \mathrm{mol} / 1$ atorvastatin) and statin-reperfusion group (normal $\rightarrow$ ischemia $\rightarrow$ reperfusion with $5 \mu \mathrm{mol} / 1$ atorvastatin). Firstly, $\mathrm{I}_{\mathrm{Na}}$ were recorded in normal $\mathrm{I}_{\mathrm{Na}}$ solution (for control) by whole-cell patchclamp. Then, in simulated ischemia solution, $\mathrm{I}_{\mathrm{Na}}$ were recorded from 3 min 